\title{
Understanding Yoga as a Therapy
}

\author{
Bhavanani $\mathrm{AB}^{*}$ \\ Centre for Yoga Therapy, Education and Research, Sri Balaji Vidyapeeth, India \\ Submission: August 03,2016; Published: September 09, 2016 \\ *Corresponding author: Ananda Balayogi Bhavanani, Centre for Yoga Therapy, Education and Research, Sri Balaji Vidyapeeth, Pondicherry, \\ India.
}

\section{Perspective}

Yoga may be said to be as ancient as the universe itself, since it is said to have been originated by Hiranyagarba, the causal germ plasm itself. This timeless art and science of humanity sprouted from the fertile soil of Sanathana Dharma, the traditional panIndian culture that continues to flourish into modern times [1-4]. Today, Yoga has become popular as a therapy, and most people come to it seeking to alleviate their physical, mental and emotional imbalances. We must understand, however, that the use of Yoga as a therapy is a much more recent happening in the wonderful long history of Yoga which has historically served to promote spiritual evolution. Yoga helps unify all aspects of our very being: the physical body, in which we live our daily life; the energy body, without which we will not have the capacity to do what we do; the mind body, which enables us to do our tasks with mindfulness; the higher intellect, which gives us clarity; and finally, the universal body, which gives us limitless bliss $[5,6]$.

All aspects of our life physical, energetic, mental, intellectual and universal are unified through the practice of Yoga, which may also be described as the science of right-use-ness, that is, of using our body, emotions, and mind responsibly and in the most appropriate manner. One of the best definitions of Yoga given by Swami Gitananda Giri is that it is a 'way of life' [7,8]. It is not something you do for 5 minutes a day or 20 minutes a day. It is indeed a $24 \times 7 \times 365$ lifestyle.

Illness, disease and disorders are so common in this world, and people everywhere are desperately seeking relief from their suffering. Yoga helps us to think better and to live better; indeed, it helps us improve ourselves in everything we do. Hence it holds out the promise of health, well-being and harmony. According to the Bhagavad Gita, an ancient text which can be said to be a Yoga Shastra (seminal textual source of Yoga), Lord Krishna the Master of Yoga(Yogeshwar) defines Yoga as "dukkhasamyogaviyogam yoga samjnitham" meaning thereby that Yoga is the disassociation from the union with suffering. Pain, suffering, disease -Yoga offers a way out of all of these $[5,6,9,10]$.

One of the foremost concepts of Yoga therapy is that the mind, which is called adhi, influences the body, thus creating vyadhi, the disease. This is known as the adhi vyadhi or adhija vyadhi, where the mind brings about the production of disease in the physical body. In modern language, this is called psychosomatic illness [11]. Virtually every health problem that we face today either has its origin in psychosomatics or is worsened by the psychosomatic aspect of the disease. The mind and the body seem to be continuously fighting each other. What the mind wants, the body won't do, and what the body wants, the mind won't do. This creates a dichotomy, a disharmony, in other words, a disease. Yoga helps restore balance and equilibrium by virtue of the internal process of unifying mind, body and emotions. The psychosomatic stress disorders that are so prevalent in today's world can be prevented, controlled and possibly even cured via the sincere and dedicated application of Yoga as a therapy.

Psychosomatic disorders go through four major phases. The first is the psychic phase, in which the stress is located essentially in the mind. There is jitteriness, a sense of unnatural tension, a sense of not being 'at ease'. If the stress continues, the psychic stage then evolves into the psychosomatic stage. At this point, the mind and body are troubling each other and fluctuations, such as a dramatic rise in blood pressure, blood sugar or heart rate, begin to manifest intermittently. If this is allowed to continue, one reaches the somatic stage, where the disease settles down in the body and manifests permanently. At this stage, it has become a condition that requires treatment and therapy. In the fourth, organic stage, the disease settles permanently into the target organs. This represents the end stage of the disease.

Yoga as a therapy works very well at both the psychic and psychosomatic stages. Once the disease enters the somatic stage, Yoga therapy as an adjunct to other therapies may improve the condition. In the organic stage, Yoga therapy's role is more of a palliative, pain relieving and rehabilitative nature. Of course the major role of Yoga is as a preventive therapy, preventing that which is to come. Maharishi Patanjali tells us in his Yoga Darshan, "heyamdukkhamanagatham"-prevent those miseries that are yet to come $[1,11]$.

If the practice of Yoga is taken up during childhood, we can prevent so many conditions from occurring later on in life. This is 
primary prevention. Once the condition occurs, once the disease has set in, we have secondary prevention, which is more in the nature of controlling the condition to whatever extent we can. Tertiary prevention is done once the condition has occurred, as we try to prevent the complications, those that affect the quality, and even the quantity, of a patient's life [9].

I would like to conclude this perspective with a word of caution. Yoga therapy is not a magic therapy! It is not a 'one pill for all ills'. There should be no false claims or unsubstantiated tall claims made in this field. Yoga therapy is also a science and must therefore be approached in a scientific, step-by-step manner. It should be administered primarily as a 'one on one' therapy that allows the therapist to modify the practices to meet the needs of the individual. It is not a "one size fits all" or "one therapy fits all" approach

When we use Yoga as a therapy, we need to consider both the nature of the person-his or her age, gender and physical condition and the nature and stage of the disorder. A step-bystep approach must include a detailed look at all aspects of diet, necessary lifestyle modifications, attitude reconditioning through Yogic counseling, as well as the appropriate practices. All of these are integral components of holistic, or rather, wholesome Yoga therapy. When such an approach is adopted, tremendous changes will manifest in the lives of the patients and their families. The quality of life improves drastically and, in many cases, so does the quantity.

As human beings, we fulfill ourselves best when we help others. Yoga is the best way for us to consciously evolve out of our lower, sub-human nature, into our elevated human and humane nature. Ultimately, this life giving, life enhancing and life sustaining science of humanity allows us to achieve in full measure the Divinity that resides within each of us.

I wish you a happy, healthy and fruitful Sadhana in Yoga. May your potential manifest in a wholesome, harmonious manner.

\section{References}

1. Feuerstein G (2001) The Yoga Tradition: Its history, literature, philosophy, and practice. Prescott Ariz: Hohm Press, USA.

2. Bhatt (2004) The Forceful Yoga: Being the Translation of Hatha Yogapradipika, Gheranda-samhita and Siva-samhita. (P. Singh, R. Bahadur, \& S. C. Vasu, Trans.) Motilal Banarsidass Publishers, India.

3. Bhavanani (2010) The history of yoga from ancient to modern times. Satya Press, India.

4. Sovik R, Bhavanani AB (2016) History, Philosophy, and Practice of Yoga. In: Khalsa SB, et al. (Eds.), The Principles and Practice of Yoga in Health Care. East Lothian, UK: Handspring pp. 17-29.

5. Feuerstein G (2003) The Deeper Dimension of Yoga Theory and Practice. Boston Massachusetts: Shambala Publications Inc, USA.

6. Bhavanani AB (2013) Yoga Chikitsa: Application of Yoga as a therapy. Pondicherry, India: Dhivyananda Creations.

7. Giri GS (1976) Yoga: Step-by-step. Satya Press, India.

8. Giri GS (1999) Ashtanga Yoga of Patanjali. Satya Press, India.

9. Ramanathan M (2007) Applied Yoga-Application of Yoga in Various Fields of human Activity. Puducherry: Aarogya Yogalayam.

10. Bhavanani AB (2014) A primer of yoga theory ( $4^{\text {th }}$ ed). Dhivyananda Creations, India

11. Bhavanani AB (2011) Understanding the yoga darshan. Dhivyananda Creations, India. 